\title{
The Two Mechanisms behind the Influence of Social Capital on Academic Development of English Teachers in Universities of China
}

\author{
Liu Hong ${ }^{1}$ \\ ${ }^{1}$ College of International Studies, Southwest University, Chongqing, China \\ Correspondence: Liu Hong, College of International Studies, Southwest University, 400715, Chongqing, China. \\ E-mail: lovelykitten@163.com
}

Received: July 10, 2013 Accepted: July 24, 2014 Online Published: August 20, 2014

doi:10.5539/ass.v10n17p244

URL: http://dx.doi.org/10.5539/ass.v10n17p244

\begin{abstract}
Based on the theory of social capital, the present study is to explore the academic development of English teachers in universities of China, and aims to identify the mechanisms behind this issue by utilizing a semi-structured interview research method. Through interviewing six subjects, this study finds that mechanisms behind the influence of social capital on academic development of English teachers in universities are group dynamics and resource vesting. Based on the findings, this study explores what countermeasures in universities should be taken to promote the academic development of English teachers.
\end{abstract}

Keywords: academic development, English teachers in universities, group dynamics, resource vesting, social capital, semi-structured interviews

\section{Introduction}

At the present time, under the background of discipline construction, academic innovation and scientific research are two core strategies to develop academic excellence for colleges and universities. Under this epoch theme, a vigorous research activity from the university teachers becomes an important issue, because the academic excellence of a university is ultimately founded on the scientific vigor of its educational and research task force. English teachers in universities, being part of this task force, in principle contribute significantly to the implementation of such strategic academic developmental plan of the universities. Unfortunately, the real-life situation shows many weaknesses and difficulties of accomplishing their mission. How to improve the research capacity of English teachers in universities to mitigate the current situation has become the concern and topic of many scholars. Yang Zhong, Zhang Shaojie, \& Xie Jiangwei (2001) analyze the causes of weakness in academic development of English teachers in universities of China, and they find six causes: first, the subject knowledge structure is not reasonable; second, interdisciplinary knowledge structure is not comprehensive enough; third, the lack of scientific awareness and scientific spirit; fourth, less research time, poor research environment; fifth, the lack of organizers and academic leaders; sixth, the lack of professional crisis and the crisis of survival. In addition, Wang Xiaoli \& Han Jianghong (2011) argue that the current domestic foreign doctoral graduate enrollment is so small that the vast majority of foreign language teachers can not be given the opportunity to pursue a doctoral degree to improve the research capacity. Many scholars (Dai, 2009; He, Huang, Qin, \& Chen, 2008; Wang \& Han, 2011) have mentioned that due to the small number of foreign language academic journals in China, it is difficult to meet the needs of foreign language teachers to publish their papers, which may restrict foreign language teachers to enhance research capacity and research initiative. The researchers are actively exploring the countermeasures to improve the research capacity of English teachers in universities of China, such as these recommendations (Wang, 2005): first, constantly update the theoretical knowledge; second, concern the academic trends; third, collect relevant information for academic innovation; fourth, combine teaching and research, promote various cooperation; fifth, focus on research methods, emphasize on academic level.

Previous studies on the academic development of English teachers in universities focus on the status, causes and countermeasures, which has made a seminal contribution in this field. However, most of the research are describing a phenomenon and the experience with the lack of a theoretical basis. Most of the previous studies also lack empirical research, which makes the results of the studies seem to have a color of more subjective inference. Therefore, this article will be the first to adopt social capital theory to study the academic development 
of English teachers in universities of China. Compared to the previous studies, the research model in this article has a stronger explanatory power of the theory, and this article is an empirical research in which the analysis of the survey data can make a more accurate and objective conclusion. So this article will have significant theoretical and practical implications in the field of the academic development of English teachers in universities of China.

Based on the theory of social capital, the present study intends to explore the academic development of English teachers in universities, and aims to identify the mechanisms behind this issue by utilizing a semi-structured interview research method. Agreeing with Nan Lin's (2001) view of social capital, this study defines social capital as various social resources embedded in social networks that can be invested and accessed in purposive actions. In the theoretical framework of academic development, the notion of academic development is divided into three dimensions: scientific awareness, research capacity and research achievements.

\section{Methodology}

This study utilizes semi-structured interviews, because a semi-structured interview is a kind of open interview carried out in accordance with the interview outline, and a semi-structured interview has the advantage of both maintaining a high correlation with the concept and theme of the study, and keeping on high reactivity of the subjects. The purpose of this semi-structured interview is to reveal the mechanisms behind the influence of social capital on academic development of English teachers in universities.

\subsection{Subjects}

Based on the three variables of gender, job title, and education background, the researcher selected six subjects. The following table illustrates their demographic information.

Table 1. Participants interviewed

\begin{tabular}{cccc}
\hline Serial Number & Gender & Job Title & Education Background \\
\hline A1 & male & professor & doctor \\
A2 & male & associate professor & master \\
A3 & male & lecturer & bachelor \\
B1 & female & professor & master \\
B2 & female & associate professor & doctor \\
B3 & female & assistant & master \\
\hline
\end{tabular}

\subsection{Procedures and Implementation}

In order to improve the effect of the interview, the researcher first carried out the test of the interview. The researcher interviewed two teachers for 60 minutes. To make up for the inadequacy of the record, the researcher used a digital recorder for recording the interview process. After this interview test, the researcher contacted the two teachers with a 30 minutes' feedback and communication, which made the researcher better understanding of the two teachers' feelings about the interview, at the same time got their suggestions to the interview. The researcher next carried out the transliteration word by word of the two recordings, then repeatedly read the transliteration text and the interview outline, and reflected on the methods and techniques used in the process of interview, to be fully prepared for the formal interview.

In the formal interview, the researcher used a recording pen for recording in the interview process. On the choice of the ways of interview, the researcher made a face to face interview with English teachers in universities of Guiyang city where the researcher lives in, and made a telephone interview with other English teachers in universities of long distance. On the interview schedule, the researcher contacted the six interview subjects for 60 minutes per interview. In the interview process, the researcher gave priority to "active listening", and from time to time used language or nonverbal feedback to keep the interview fluency. In addition, for some vague answer the researcher timely asked more clarifying questions to get clear and complete information, while for some answer implying certain research value, the researcher timely asked more exploratory questions to get rich information of research value. When arranging the interview transcription, the researcher contacted the interview subjects by QQ for inquiring and verification, to ensure the clarity and pertinence of the information in the transcription. 


\section{The Research Finding}

Based on the theory of social capital, analyzing the interview data, this study attempts to put forward two concepts of "group dynamics" and "resources vesting" in order to reveal the mechanisms behind the influence of social capital on academic development of English teachers in universities.

\subsection{The First Research Finding of the Semi-structured Interview: Group Dynamics}

Based on the notion that social capital are various social resources embedded in social networks, this study attempts to put forward the first form of mechanism behind the influence of social capital on academic development of English teachers in universities: group dynamics. Group dynamics is the result of the carrier of social capital: social relation network. Because the person has social nature, he or she lives in a big or small, intimate or alienated social relationship network, and can not survive if the person left the social relation network. So the relationship network will have the important influence on "psychological activity and behavior" (Shao, 2007:39) of individuals in the relationship network. In this study, group dynamics refers to a kind of form that the social network influences on academic development of English teachers in universities.

If members of the social relation network are focusing on research and have made certain academic achievements, this spiritual pursuit and associated behavior of scientific research in the social relation network can form a sense of values and norms. Due to the values and norms are the manifestation of social capital, English teachers in universities may have the social capital which contains good scientific research value. Such social capital through the mechanism of group dynamics can stimulate or even force English teachers in universities to be engaged in scientific research and to improve their academic achievements.

Through interviewing six participants, the researcher has found that the participants' answers strongly support the mechanism of group dynamics .

Interviewer: Will the people of the academic circle that you associate with bring help to your scientific awareness?

\section{Participant A1 (male, professor, doctor):}

Well, some help. I think this help is relatively big. In the academic community, ah, we often say that we can obtain a kind of connections, academic connections, and then in the academic contacts we can know more people. So, our scientific awareness will increase, because as we all know, to compare ourselves with the people around us is a common sense of Chinese thinking. That is to say, the members' age, title, educational background, and the academic achievement in the academic community is a kind of incentive to us.

Interviewer: What is the help that the academic community brings to your academic research?

\section{Participant A2 (male, associate professor, master):}

$O k$, it is a very big help. Not to participate in academic activities, well, I feel it hard to open my research field of vision, and I don't know whom to say when I sometimes feel confused in research. Well, it will be very upset. Later, after attending academic activities, I feel very happy, because I have found that in academic activities I open the research field of vision. Besides, the teacher's positive remarks and enthusiasm for research infects me to a great extent, which makes me more consciously participate in the research. Let me put it this way, in the academic activities some experts not only solve my confusion, and, more importantly, bring me the academic frontier information, so now I often attend academic activities.

Interviewer: Please talk about your academic status in the last two or three years?

\section{Participant A3 (male, lecturer, bachelor):}

Well, talk about my research, now I am a little embarrassed. Colleagues around me, most of them are master degree, every year there are two or three who can embark on a PhD. However, as for me, I can't seem to be very motivated, because I am still an old bachelor. Actually I am eager to go to read for a master, and if I can read for a doctor in the future, ha -, become a master in research, that is the best.

Interviewer: It is very rare that you are a female professor, please talk about your research experience?

\section{Participant B1 (female, professor, master):}

Not much experience, colleagues say I am a strong woman. Actually I just spend more time on the research. Now social competition is so big, the work unit as well, and the condition of professional evaluation is higher every year. Everyone is busy with papers and projects, so if I don't become a professor earlier, it will be harder for me to become a professor. So I spend more time on research, I couldn't help doing it. 
Interviewer: Now, working in universities need to be highly educated and have high titles, how do you think about this problem?

\section{Participant B2 (female, associate professor, doctor):}

Universities are now so, to be a doctor and professor is very fashionable. After all, it is a result of competition. As for me, I see that there are more and more doctors in our unit, which gives me much pressure. Later, I also went to embark on a doctor, and using the period of studying for a doctor's degree I make efforts to publish some papers which make me become an associate professor. My ideal is to try more efforts to do research in a few years, and become a professor before the age of 45.

Interviewer: Please talk about the difficulties in your research?

\section{Participant B3 (female, assistant, master) :}

Well, a lot of difficulties. Well, I just get a master's degree, so, my title is low, and I have less academic achievements if I'm compared with colleagues. Well, recently I'm married, if I had a baby, I would have no time to write a paper, so in two years I must work hard to write more papers to pass the evaluation of associate professor. I think, it is difficult for me.

The interview result shows that the academic organization and work unit, these two kinds of organizational social capital, have a significant effect on the academic development of English teachers in universities. The conformity theory of social psychology tells that under the pressure of group individuals will behave the same as the group, which can be used to explain the above phenomenon. The six participants' answer also confirms this view. When the organizational social capital of English teachers in universities has high academic content, the organizational social capital under the action of the conformity psychology can promote the English teachers in universities to consciously engage in academic research through the group dynamic mechanism.

\subsection{The Second Research Finding of the Semi-structured Interview: Resource Vesting}

Based on the notion that social capital are various social resources embedded in social networks, this study attempts to put forward the second form of mechanism behind the influence of social capital on academic development of English teachers in universities: resource vesting. Resource vesting is the result of the social capital's attribute of social resources. The individual's investment of social capital is to make the social capital endow them with some kind of social resources. As for this study, if the social capital of English teachers in universities contains more academic resources, they can get advantageous academic resources to promote their academic development through the mechanism of resource vesting.

Through interviewing six subjects, the researcher has found that the participants' answer strongly supports the mechanism of resource vesting.

Interviewer: Oh, good. what kind of impact will your school's library, academic team and teaching team bring to your scientific awareness?

\section{Participant A1 (male, professor, doctor):}

Good library, we say, will ask the backbone teacher or academic leaders to collect the research data of current problems in the academic frontier, which will bring an academic team good foundation of data. So is our library. For example, our school library will frequently ask us to collect some foreign language materials which are the books we need to purchase in our research field. As for the academic team, it is good to establish an academic team where the members can share the academic information and get academic suggestions, which may provide the members with help to their research.

Interviewer: Will the academic organization you participate in bring help to your research achievements?

\section{Participant A2 (male, associate professor, master):}

To participate in the academic organization can provide a lot of help to publish my papers. To attend the conference, my paper can be published in the conference proceedings. Among the experts in the conference, there are some academic journal editors who can help me to publish my papers. Well, if I don't participate in the academic activities, it will be hard to acquaint myself with these experts. As a result, the opportunity to publish papers must be much less.

Interviewer: What is the effect of your school's academic policies on your scientific awareness? 


\section{Participant A3 (male, lecturer, bachelor) :}

Alas, our school is just an ordinary university where the research policy is not very good and the research environment is ordinary. As the school is not for the sake of the teacher, the school will not provide fund for the publishing fee of teachers' papers. What's more, the publishing fee is not a small sum of money, so I have no interest in writing a paper, not to say to publish it. Our school library is not good and has just a few foreign data. Under such circumstance, I don't even want to write a paper.

Interviewer: What is the effect of your school's academic policies on your scientific awareness?

\section{Participant B1 (female, professor, master):}

Yes, I think, the school's academic policy is particularly important. I have a classmate whose school's academic policy is very good. If a teacher published a paper in an authoritative journals, the teacher could get a reward of a lot of money. If our university paid the publication fee, the teacher would be much more interested in writing an essay or writing a book. I think, our school have not done well in the academic policy which needs to be improved.

Interviewer: What kind of academic policy could bring help to your research?

\section{Participant $\mathbf{B} 2$ (female, associate professor, doctor):}

Well, well, I think, if schools scientific bureau and other leaders take part in public activities with the higher official for the sake of teachers, teachers will have more chances to get a project. If the leaders of the school organized experts to review our project declaration and gave us revising suggestion, we could get more chance to succeed in getting a project. I have heard that many universities outside our province are under such operation, but unfortunately I feel our university fails to do so.

Interviewer: What kind of help do you need on the research?

\section{Participant B3 (female, assistant, master):}

Well, I'm just a green hand, so I don't have much experience in teaching and research, which makes me eager to get the guidance on teaching and research from the senior professor. I hope that the school can let me join a team and often participate in the activities of the team's teaching and research. Thus in the team I can get the guidance of the experts, which will help me to walk less detours.

The six subjects' answers stress the importance of academic resources of work unit and academic organization. If English teachers can get enough academic resources from the work unit and academic organization, it will be a great help to improve the teacher's scientific awareness, research capacity and research achievements, which gives us further instructions that these two kinds of organizational social capital have a more significant effect on the academic development of English teachers in universities.

\section{Discussion and Enlightenment}

As for the mechanism behind the influence of social capital on academic development of English teachers in universities, this study finds group dynamics and resource vesting. Liu Guoquan (2010) concluded that the path of influence of social capital on academic performance means both internal support and external support through interviews. The internal support refers to such behaviors as helping analysis of research dynamics, modifying the study design which is in the ontology process of research, while external support refers to the assessment and research award of the scientific research project. These two paths are equivalent to the mechanism of resource vesting, namely teachers will obtain academic resources through the mechanism of resource vesting of social capital. Because Liu Guoquan (2010) focused on the influence of social capital on teachers' research performance, and this study expanded the aim of study to teachers' academic development, this paper comes to another conclusion that group dynamics is also a mechanism behind the influence of social capital on academic development of English teachers in universities. This discovery is a beneficial supplement to Liu Guoquan (2010)'s study.

This study's main enlightenment is that universities should make full use of the mechanism behind the influence of social capital on academic development of English teachers to promote their academic development. This study has found that the mechanism consists of two forms: group dynamics and resources vesting. So, in the policy making, the universities should step up research support for English teachers to give them more resources. In view of the finding that the social capital of academic organization has bigger influence on academic development of English teachers, universities should pay full attention to the importance of the academic activities to English teachers' academic development. What's more, universities should actively invest capital and manpower for organizing specialized academic activities for English teachers, and formulate preferential 
policies to encourage English teachers to actively take part in all kinds of academic organization to absorb and mobilize the academic resources in such organization. Universities should be supportive to establish teaching teams or academic teams, and encourage all English teachers to participate in, in order to make the academic resources benefit each English teacher in a more balanced status.

Secondly, universities should make use of the mechanism of group dynamics, which means that universities can reward the good and fine the bad in teacher's annual performance appraisal of academic achievement to establish the value that the good English teachers should be good at academic development. Once this value is established in the group of English teachers in universities, which will greatly improve the research atmosphere, and then under the action of the conformity psychology, larger incentive effect may be produced on the psychology and behavior of the individuals in the group. As a result, the effect of the mechanism of group dynamics is prominent, subtly driving English teachers in universities to make greater academic development.

\section{References}

Dai, W. D. (2009). A review and outlook of 60 years of professional foreign language education in China. Foreign Languages in China, 5, 10-15. Retrieved from http://www.docin.com/p-294435014.html

He, Q. X., Huang, Y. S., Qin, X. B., \& Chen, J. P. (2008). Retrospect and prospect of the nearly 30 years of teaching for English majors in Chinese universities. Foreign Language Teaching and Research, 6, 427-432. Retrieved from http://www.doc88.com/p-9015923577767.html

Lin, N. (2001). Social Capital: A Theory of Social Structure and Action. Cambridge University Press.

Liu, G. Q. (2010). The Study of the Influence of University Teachers' Social Capital on Their Academic Performance (Unpublished doctoral dissertation). Peking University, Beijing, China.

Putnam, R. D. (1995). Bowling alone: America's declining social capital. Journal of Democracy, 6(1), 65-78. Retrieved from http://www.looooker.com/archives/1579

Shao, P. R. (2007). Communication. Beijing: Higher Education Press.

Wang, J. J. (2005). Scientific research quality of college English teachers. The Study of Teacher Training, 3, 54-58. Retrieved from http://wuxizazhi.cnki.net/Search/SZPX200503012.html

Wang, X. L., \& Han, J. H. (2011). Current situation and development bottleneck of scientific research of foreign language teachers in universities: An empirical perspective. Foreign Language World, 3, 44-51. http://wenku.baidu.com/view/d068263f650e52ea5518984f.html

Yang, Z., Zhang, S. J., Xie, J. W. (2001). The present research situation and problem analysis of college English teachers. Foreign Language Education, 6, 79-83. Retrieved from http://www.cnki.com.cn/Article/ CJFDTOTAL-TEAC200106017.htm

\section{Copyrights}

Copyright for this article is retained by the author(s), with first publication rights granted to the journal.

This is an open-access article distributed under the terms and conditions of the Creative Commons Attribution license (http://creativecommons.org/licenses/by/3.0/). 